\title{
Institutional imperatives for sustainable socio-ecological and economic development
}

\author{
Marina Kandrokova ${ }^{1}$, Salima Makhosheva ${ }^{1}$, Aslizhan Efendiev $^{1}$, Halimat Uyanaeva ${ }^{1}$, and \\ Batraz Dzgoev ${ }^{2, *}$ \\ ${ }^{1}$ Institute of Informatics and Regional Management Problems of KBSC RAS, 20, Pushkin str., 360006, \\ Nalchik, Russia \\ ${ }^{2}$ North Caucasian Mining and Metallurgical Institute (State Technological University), 44, Nikolaeva \\ str., 362021, Vladikavkaz, Russia
}

\begin{abstract}
The sustainable growth of the modern economy is based on socio-ecological and economic development. One of the key development trends on a global scale is the formation of an innovative type of economy, and, as a consequence, in the process of economic development of most countries, including Russia, the need to create an institutional environment corresponding to a new type of economic growth comes to the fore. Accordingly, the need to create an adequate, adaptive to regional characteristics, assessment of the institutional environment of the region, to create mechanisms for its measurement, to establish indicators of efficiency increases. Firstly, indicators of the effectiveness of institutions will make it possible to visualize the process of development of the region and thereby increase its investment attractiveness. These indicators will stimulate the interest of business representatives and, first of all, those who are ready to invest their funds and are looking for territories that satisfy them according to all the criteria necessary for successful commercial activity and profit in the future. Secondly, measuring the effectiveness of regional institutions allows federal authorities, the public, and even various international financial organizations and aid funds that provide loans and multifaceted support, including admission to clubs in the developed world, to adequately assess the activities of local power structures, for which the growth of institutional indicators in the region is one of the key intentions contributing to the increase of their authority and the attractiveness of the territory as a whole. Thirdly, the assessment of the institutional environment allows specialists, on the basis of available indicators, to determine both the advantages and advantageous competitive positions of the economic system as a whole and its vulnerabilities, make sound economic forecasts for the near future and analyze the impact of such factors as the state politics, social structure, traditions, moral norms, history, geography, and natural resources on the state of the institutional environment.
\end{abstract}

* Corresponding author: angela-1309.m@yandex.ru 


\section{Introduction}

The indicators of the quality of institutions existing in the countries of the world are numerous and varied: from the degree of effectiveness of the activities of the authorities to the ability of the state to create comfortable conditions for doing business and to ensure the protection of property rights on its territory [1].

Since in Russia, with its vast territory and constituent entities that significantly differ in the effectiveness of local authorities, socio-economic and geographical, climatic conditions, in terms of living standards and well-being of the population, the activity of the entrepreneurial community and, as a result, their overall investment attractiveness, the existing criteria for the evaluation of the institutional environment, intended for assessing the entire country, smooth out the specified features of individual territories [2], along with the quality of state institutions, the state of institutions in the regions should also be taken into account. The active formation of the rating and index system, which reveals the quality of the regional institutional environment, began fifteen years ago and continues to this day. The number of indicators has already exceeded several dozen, which, in our opinion, necessitates their ordering according to general features and determining their reliability and practical significance, since it is already quite difficult for specialists in the field of studying the institutional environment of regions to understand so many different indices and ratings. Nowadays, this problem has not been thoroughly analyzed by economists.

Purpose of the study. Analyze the well-known indicators that determine the level of development of institutions in the regions and find out how they are interrelated. Systematize data sources, propose an adaptive system of indicators for assessing the institutional environment of the region based on the characteristics of the regional economy.

The identification of sufficiently high and statistically significant indicators of the relationship of most of the indicators of the state of institutions with each other indicates institutionally prosperous constituent entities of the Russian Federation or outsiders, while their insufficient interdependence indicates a kind of non-uniformity of the institutional environment of the region and the absence of a constant connection of indicators with each other. In these circumstances, we consider it expedient to combine individual indicators into integral indices. This will make it possible to identify different types of institutions, leading such characteristics as the unconditional primacy of federal and regional legislation, developed competitive economy, prevention of corruption offenses, etc. to key ones.

At the same time, such institutions, by default, are generalized and transcendental phenomena, in other words, theoretical constructions. Therefore, the question of the availability of their measurement and the need to confirm the results empirically through the use of private indices arises quite naturally. In this case, in the process of measuring institutions, one should use all the variety of elements of the real space within which economic activity is carried out.

Of course, it seems more preferable and effective to study individual regions within one country than the analysis of the correlation of institutions and development, which is widespread in the literature [3]. To represent such relationships, it is more expedient, in our opinion, to use statistical models, since all subjects of the Russian Federation operate in the same legal field regulated by a general federal law, in identical socio-political conditions, and have a single economic system. Besides, the interpenetration of institutions is caused by the long-term joint history, cultural characteristics of the peoples living here, etc. In addition, the error due to "missing variables" in the course of an interregional study in regression models will be minimal, since different constituent entities of one state correspond more to the well-known ceteris paribus formula (all other things being equal). 


\section{Methods}

The first attempts to measure institutions are found in investment ratings compiled by private agencies at the request of interested investors to determine the possibility of establishing business ties in a particular country and investing in business projects. In the early 90 s of the twentieth century, scientists dealing with this issue experienced some difficulties, including practical and methodological ones [4].

First of all, the measurement of institutions needs to be separated from the state of the economy in view of the ongoing discussions about their importance in economic development [5]. Their apparent inseparability in measuring institutions threatens tautological parallelism and, unfortunately, makes the approach to measuring institutions formal and procedural, as well as unproductive, on the grounds that the set of such requirements does not correlate with the results achieved in practice. That is, the long-term rules of interaction between economic and political players, such as constitutional ones or limiting the arbitrariness of the authorities, are undeniable in themselves. However, under certain conditions, lacking historical, cultural and other substantiations and even more informal mechanisms of execution, they can be violated in practice [6].

So, we came to the conclusion that formal institutions play an important role only taking into account the practice of implementing the restrictions and the conditions that they establish. To assess these practices, a qualitatively different approach is required, in contrast to the formal and procedural approach that clearly does not work in this case.

An alternative method, most often used in measuring institutions, is the study of subjective assessments and judgments of experts, as well as formed relatively stable opinions of users of institutions. Of course, it will not be easy to isolate the noisiness from such results. At the same time, it is it who will show whether the distortions during aggregation are random or systematic. If these noises are not correlated, when aggregating the survey results, the randomness of opinions will not particularly affect the result, but regular ones are quite expected [7].

The experts taking part in the survey easily highly rate the institutions of prosperous countries with stable economies [8], while in poor countries with an unstable political system and depressed economies, the assessments of institutions are expectedly low.

The legitimacy of such an assessment is obvious, since the peculiar abstractness of institutions does not allow monitoring in a traditional form. Therefore, it seems legitimate and natural to draw conclusions about, in essence, a speculative concept based on indicators that can be observed and analyzed, as well as indirectly related to it.

However, the inverse causal relationship of the results obtained in this way and economic indices casts doubt on the statistical relationships identified in the above way. An illustration of bypassing (unhindered one) formal regulations can be the situation when there is no connection at all, let alone a systematic one, between the quality of monetary policy in the state and the existence of a law on the independence of the Central Bank [9].

In order to avoid such risks, the existing methodological methods for measuring institutions for comparing different countries use standard conditions, including the costs of identical administrative actions. These are registration of a business, obtaining a compulsory license [10], consideration of controversial issues of a commercial nature, as well as the frequency of occurrence of various institutional traps and the same destructive distortions in the structures of institutions, including market expansion, forced seizure of property, illegal takeover, etc.

Representatives of the expert community, analysts, small and medium-sized businesses can assess the state of the constitutional environment in terms of such parameters as the competence and performance of civil servants, the level of corruption and the amount of abuse of officials, the impartiality of the judiciary, the level of competition, etc. [18]. The 
calculation is based on the fact that a specific formulation of questions, a detailed consideration of all the details and the unification of measurement algorithms will lead to minimization of errors, and the objectivity and reliability of the results are confirmed by the fact that when assessing institutions for subsequent generalization and systematization, many indicators from various sources are used.

It is these criteria that govern one of the most popular developments in the study of the institutional environment of various states - "Governance Matters" [11]. Their main goal is to systematize the multitude of currently available various institutional indices, integrate them into groups according to common characteristics, depending on the dimensions of institutions. The creators of the rating suggest conducting research on the following indicators: political stability and security, quality of regulation, efficiency of government work, prevention of corruption. Moreover, only assessments based on the personal perception of the research participants are taken into account and analyzed.

The developers of the project explain their decision by the fact that in the economy, almost all actions are performed under the influence of such perceptions, which means that the applied indices can most likely be used when studying the role of institutions in the development of the economy.

The described indices are already systematically used in many scientific studies on economics, which, on the one hand, explain the quality of institutions operating on the territory of various countries of the world, on the other hand, explain the results of economic activity with the help of institutions. In addition, they are successfully used in a variety of international projects and programs [12].

But despite this, many experts doubt the objectivity of the methods used by Governance Matters due to the obvious inaccuracies in the measurements of institutions and the uncertainty of the object of study itself, and the six mentioned clusters are too abstract and combine a variety of aspects of economic activity. In particular, in legal, political and economic practice, corruption has many types and forms of manifestation: from petty everyday corruption, bureaucratic corruption of low-ranking officials to high and very high-level corruption, including political corruption affecting the interests of the entire country and its population.

Thus, due to the uncertainty and terminological ambiguity of the definitions of the clusters into which the indices of the institutional environment are grouped (as in the example with corruption), it is impossible to unambiguously assign them to a certain cluster, which casts doubt on the validity of these measurement methods, and even more so that the object of evaluation is not an abstract construct, but a real objective concept [13].

The research results of the Governance Matters project show that the indices of institutions developed by it have a fairly strong statistically significant correlation (more than 70-80 percent), while the analysis of all external and internal factors reveals the main component that determines most of the total variation of indicators [14]. The presented alignment indicates the presence of strong interconnected and interdependent relations of institutional indicators, which determines the reliability of the assessment of the qualitative characteristics of the institutional environment of the regions and, in general, the work of the authorities in the country, carried out using this basic component as an integral quality indicator [15].

A similar effect is achievable provided that the state or society itself, and ideally, both of them together, have the opportunity to independently choose the institutional system and the right to use the freedom of choice exclusively in the interests of society, which implies a proportional and even formation of key institutions, since they do not replace each other, but equally complement each other [16]. Thus, the high level of corruption in the authorities and the judiciary will not be able to compensate for the investment attractiveness necessary for a favorable business environment. The presented probability is somewhat hypertrophied and 
slightly primitivizes reality from the point of view of institutional choice. In addition, it does not agree with the many institutions, as well as the various options for their connection and interweaving that exist today.

It is necessary to mention the method of assessing institutions, which refers directly to the state of the economic system. It was noted above that such a method is not entirely correct and has its weak point - the assessment of the relationship between institutions and development causes distrust due to possible errors caused by the inverse causal relationship inherent in the measurement method itself. On the other hand, this method is substantiated only if certain economic indicators are involved, showing the state of specific segments and areas of the economy, and with a high degree of confidence, the results of measuring the institutional environment can be recognized as objective.

The analysis of the measurement of institutions in different countries of the world allows making the following generalizations:

1) institutions are a multifaceted and multi-valued phenomenon, and their impact on socio-economic development is also diverse, as a result of which, for their objective assessment, it is necessary to use different methods and sources of information;

2 ) it is not always justified to structure the indices of the institutional environment "in advance", without evidence and study of actual material. In our opinion, it is preferable to structure institutional indices on the basis of already existing information, in particular, by the method of multivariate factor analysis, in order to then find an appropriate explanation for the obtained statistically representative, deterministic indicators.

Let's consider the features of the institutional environment in Russia. Each constituent entity of the Federation has its own unique microclimate, which determines the conditions for entrepreneurial activity and, accordingly, its investment potential [19]. Such differences in the degree of business security, the presence or absence of administrative barriers, infrastructure provision, access to commodity markets and other main indicators within the borders of one state are observed infrequently and inevitably affect the volume and placement of attracted capital, the scale of the informal economy, etc. [17].

For such a huge territory with so many regions located in different geographic coordinates and possessing different natural resources, the variation in institutional conditions is quite natural, since as a result of the uneven distribution of the population actively participating in the production process and business, different levels of accessibility of external and internal commodity market, developed infrastructure and resources, there are a division and regionalization of institutions [18].

Theoretically, the reasons for the interregional variability of institutions in the Russian Federation are undoubtedly objective, but in practice, the differences are much more serious and widespread than it would be logical to assume for a single territory with a centralized state power, a common administrative system and fiscal policy. At the same time, one should also take into account the low activity of Russian subjects in terms of legislative initiatives.

All this allows drawing a conclusion about the almost unsystematic and inconsistent application of Russian regulations in the regions. In any case, institution measuring tools common for the whole country give an average assessment, which, due to the above variations, often significantly differs from the real situation on the ground, which makes it extremely topical to decide on the development of a method for an objective and reliable assessment of the quality of Russian institutions.

The heterogeneity of the institutional environment manifested itself in Russia in the 90s simultaneously with economic transformations and the transition to a market system of management and was caused by the helplessness of the governing structures, which at that time were neither unable to ensure equal conditions and approve the norms of a market economy that were in effect in all constituent entities of the Russian Federation without exception, nor competently coordinate their implementation. In Russia at that time, a "parade 
of sovereignties" was taking place, and each region hastened to seize on the offered opportunity to gain as much power as its own strengths and ambitions allow. Ultimately, status inequality was established among the constituent entities of the Russian Federation, and as a result, the so-called conservative and liberal republics were formed with their own municipal leaders and privileged groups in power structures, with different states of the economy and living standards of the population, and regions with mixed systems combining democratic principles and elements of authoritarianism.

Another possible reason was the protracted economic recession and interruptions in investment in the Russian economy, which occurred at the time of the redistribution of the functions of regional institutions. In such an unfavorable environment, foreign investors were very reluctant to make contact even with entities that could provide them with favorable conditions for cooperation, i.e. the differences in institutions in different regions almost disappeared in the shadow of the overall unstable investment reputation of the country's economy [19].

Thus, the problem of assessing regional institutions has been filled with a new administrative and political content - extremely practical. It turned out that in reality, it is not an easy task to adequately and objectively measure the activities of local authorities. For example, the multitasking of executive authorities and the difficulty in measuring the results of their activities have provoked the emergence of hundreds of new criteria for determining the effectiveness of the heads of regions. At the same time, it is quite obvious that the likelihood of using this information in practice is minimized.

In addition, if, for example, the minimum number of criteria is used, it is still not clear how to combine them and what numerical value to set for individual indicators. It is difficult to determine what caused the failures and achievements of the regions: the activities of local authorities or the market situation, the activity of the population and business structures, geographic location and other exogenous factors.

In the course of the study, in order to measure the state of the institutional environment of the region, taking into account the peculiarities of the regional economy, we propose an adaptive system of indicators, combining them into integral indices, which will more accurately determine the state of regional institutions.

To measure regional institutions, we chose such an index as the entrepreneurial climate with the following indicators: the number of days required to open a company/microenterprise, the cost of registering a company, the share of tax revenues in the total amount of the consolidated budget revenues of the region. This indicator demonstrates the availability of doing business in the region, believes the Opora Rossii agency.

Another index we have chosen consists of 2 features - investment potential and investment risks, which include a number of indicators that are basically presented in official statistical sources. They give an idea of the quality of public administration, legal and political risks, etc. These indicators are annually identified through surveys of specialists from Russian and foreign investment and consulting companies, among which they are especially scrupulously assessed by the Expert RA agency.

An important role in assessing the level of the institutional environment is played by the index of development and productivity of innovations, which is a promising area in the field of environmental regulation and the transition to sustainable development of the region and the need to support environmental projects at the initial stage, taking into account the significance in the long term of the development of the region. The index of development and productivity of innovations includes the following indicators: the number of scientific organizations, the number of personnel engaged in research and development, the receipt of patent applications and the issuance of titles of protection, the share of costs for innovative activities in the total volume of goods shipped, work and services performed, the volume of innovative goods, works, services, developed advanced production technologies, costs 
associated with environmental innovations, the share of organizations that carried out environmental innovations in the reporting year in the total number of studied organizations.

One cannot ignore the assessment of development institutions that contribute to the improvement of the institutional environment. The role of development institutions is great and manifests itself both in the socio-economic aspect and in the environmental one. The work of development institutions can be determined by such indicators as: the number of technoparks, the number of business incubators, innovation support funds, technology transfer centers, and energy conservation centers.

To determine the level of development of the knowledge economy, which makes it possible to assess the readiness of the region to switch to a development model based on knowledge, we will determine the indicators used to calculate the knowledge economy index, these are: the number of people with secondary education, the number with higher education, education expenditures ( $\%$ of GDP), unemployment rate.

We consider it important to focus on the safety of doing business (this index is calculated by the Opora Rossii business association). Let's define this index as an institution of asocial phenomena and divide it into several indicators:

1. The level of corruption in the regions (calculated using expert assessments of the situation in the region and the effectiveness of combating corruption).

2. Indicator (size) of the shadow economy (calculated by epy Federal State Statistics Service based on data from quarterly surveys, the number of people employed in the informal sector).

3. The indicator of the protection of property rights (calculated on the basis of materials published in the media about illegal seizures in different regions [1]. In addition, the Center for Public Procedures "Business against corruption" registers statements by entrepreneurs about cases of violent takeover of business, all kinds of harassment and illegal actions by law enforcement agencies [20].

Another very important and relevant indicator for assessing the institutional environment of the region is the determination of the activities of regional authorities, represented by two indicators. First of all, this is the publicity of the local self-government system - information is added to the Unified Interdepartmental Information and Statistical System. The second indicator is the activity of regional executive bodies, and indicators of the effectiveness of the performance of their functions by the local administration are calculated separately.

Table 1. A system of indicators assessing the state of regional institutions.

\begin{tabular}{|c|c|}
\hline Index & Indicator \\
\hline \multirow[t]{5}{*}{ Entrepreneurial climate } & Number of days required to open a firm / microenterprise \\
\hline & Company registration cost \\
\hline & $\begin{array}{l}\text { Share of tax revenues in the total amount of revenues of the } \\
\text { consolidated budget of the region }\end{array}$ \\
\hline & Share of products of small enterprises in GRP \\
\hline & $\begin{array}{l}\text { The number of operating credit institutions and branches for } \\
\text { every } 10,000\end{array}$ \\
\hline \multirow[t]{2}{*}{ Investment } & Investment potential \\
\hline & Investment risks \\
\hline \multirow{6}{*}{$\begin{array}{l}\text { Development and } \\
\text { productivity of innovations }\end{array}$} & Number of scientific organizations \\
\hline & R\&D personnel \\
\hline & Number of patents and licenses \\
\hline & $\begin{array}{l}\text { Share of costs for innovative activities in the total volume of } \\
\text { shipped goods }\end{array}$ \\
\hline & Volume of innovative goods, works, services \\
\hline & Number of advanced manufacturing technologies developed \\
\hline
\end{tabular}




\begin{tabular}{|c|c|}
\hline & Costs associated with environmental innovation \\
\hline & $\begin{array}{l}\text { Share of organizations that carried out environmental } \\
\text { innovations in the reporting year in the total number of } \\
\text { surveyed organizations }\end{array}$ \\
\hline Development institutions & Number of technoparks \\
\hline & Number of business incubators \\
\hline & Number of innovation support funds \\
\hline & Number of technology transfer centers \\
\hline & Number of energy-saving centers \\
\hline $\begin{array}{lll}\begin{array}{l}\text { Institute of } \\
\text { phenomena }\end{array} & \text { asocial } \\
\end{array}$ & Corruption level \\
\hline & $\begin{array}{l}\text { The number of crimes committed per } 10,000 \text { people of the } \\
\text { region's population }\end{array}$ \\
\hline & Protection of property rights \\
\hline $\begin{array}{llr}\text { Activities } & \text { of } & \text { regional } \\
\text { authorities } & & \end{array}$ & $\begin{array}{l}\text { Political competition, practicality and transparency of political } \\
\text { life }\end{array}$ \\
\hline & Effectiveness and openness of regional management \\
\hline
\end{tabular}

The proposed system of indicators for assessing the effectiveness of the functioning of regional institutions will allow us to objectively consider their importance in the socio-ecological and economic development of the constituent entities of the Russian Federation and will provide an opportunity to understand the reasons for the emergence of their heterogeneity in the constituent entities of Russia. This analysis will allow measuring the potential of institutional transformations, which is a factor in the sustainable development of regions, as well as establishing external factors on which the state of institutions in the regions depends and which promote or, conversely, oppose the implementation of institutional reforms.

In the next step, the presented system of indicators, which is measured in different units, should be calculated using the formulas:

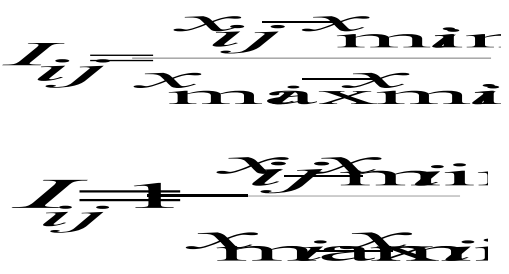

where $x i j$ - $\mathrm{i}$-th indicator of $\mathrm{j}$-th region; $x$ min $i$ - the minimum value of the $\mathrm{i}$-th indicator among all $\mathrm{j}$ regions; $x$ max $i$ - the maximum value of the $\mathrm{i}$-th indicator among all $\mathrm{j}$ regions. If the best value of the indicator was its smallest value, then the formula was transformed into the form (2).

Further, by aggregating the resulting private sub-indices, the final indicator is determined - the composite index, which will make it possible to assess the state of the institutional environment of the regions.

\section{Conclusions}

The analysis of the main approaches to measuring institutions at the intercountry level, prevailing today in the literature, is given. The result of the analysis is the extraction of conclusions and, which is especially important, recommendations regarding the measurement of institutions in Russian regions. The distinctive features of regional Russian institutions for the period from the start of market reforms to the present are revealed. 
Particular attention is paid to the prerequisites for institutional diversity in the light of economic and political decentralization.

The sources of data necessary for assessing regional institutions are systematized, and the regional ratings known in the literature are added to them. An adaptive system of indicators for assessing the institutional environment of the region is proposed, which will allow determining the importance of institutions both in social, environmental and economic development not only for the republics of the North Caucasus Federal District, but also for other typical regions.

\section{Acknowledgements}

The study was supported by the Russian Foundation for Basic Research (project No. 20-010-00281 A)

\section{References}

1. K. Schwab, N. Davis, Shaping the Fourth Industrial Revolution (World Economic Forum. Kindle Edition, 2018)

2. M.V. Kondratov, R.I. Garipov, Fundamental Research 11, 1908-1911 (2013)

3. R. Snyder, Studies in Comparative International Development 36(1), 93-110 (2001)

4. G.B. Kleiner, Economics and Mathematical Methods 39(3), 2-3 (2003)

5. G.B. Kleiner, Evolution of institutional systems (Moscow, Nauka, 2004)

6. E.V. Popov, Evolution of the institutions of mini-economics (M., Nauka, 2007)

7. D. North, Institutions, institutional change and economic performance (N.-Y., Cambridge University Press, 1990)

8. D. Finegold, Oxford review of economic policy 1 (1999)

9. A.Yu. Veretennikova, Zh.K. Omonov, Journal of Economic Theory 2, 156-162 (2017)

10. A.E. Shastitko, Journal of the New Economic Association 3(35), 177-184 (2017)

11. D. Kaufman, A. Kraay, M. Mastruzzi, Hague Journal on the Rule of Law 2, 220-246 (2011)

12. D.A. Kuleshova, Classification of development institutions based on the needs of an innovative project at different stages of the life cycle, 152-164 (2017)

13. M.V. Kondratov, R.I. Garipov, Fundamental Research 11, 1908-1911 (2013)

14. O. Williamson, The Economic Institutions of Capitalism. Firms, Markets, Relational Contracting (N.Y., The Free Press, 1985)

15. N.D. Drozdov, Institutional Economics (Tver, Tver. state un-ty, 2006)

16. S.A. Makhosheva, N.Y. Rud, M.M. Kandrokova et al., Revista Espacios 47 (2018)

17. E.N. Sidorova, D.A. Tatarkin, Vestnik UrFU. Economics and Management Series 15, 506-528 (2016)

18. A. Yakovlev, A. Sobolev, A. Kazun, Post-Soviet Affairs 30(2-3), 171-194 (2014) 